\title{
Curiosity Rover Mars Hand Lens Imager (MAHLI) Views of the Sediments and Sedimentary Rocks of Gale Crater, Mars
}

Kenneth S. Edgett ${ }^{1}$, R. Aileen Yingst ${ }^{2}$, Michelle E. Minitti ${ }^{2}$, Megan R. Kennedy ${ }^{1}$, Gillian M. Krezoski ${ }^{1}$, Deirdra M. Fey ${ }^{1}$, Stéphane Le Mouélic ${ }^{3}$, Scott K. Rowland ${ }^{4}$, Linda C. Kah ${ }^{5}$, Ezat Heydari ${ }^{6}$, James B. Garvin ${ }^{7}$, Scott J. VanBommel ${ }^{8}$

1. Malin Space Science Systems, San Diego, CA, USA.

2. Planetary Science Institute, Tucson, AZ, USA.

3. Laboratoire de Planetologie et Geodynamique, CNRS, Université de Nantes, France.

4. University of Hawai i, Honolulu, HI, USA.

5. University of Tennessee, Knoxville, TN, USA.

6. Jackson State University, Jackson, MS, USA.

7. NASA Goddard Space Flight Center, Greenbelt, MD, USA.

${ }^{8 .}$ University of Guelph, Guelph, Ontario, Canada.

The Mars Science Laboratory rover, Curiosity, landed in Gale crater in August 2012 to investigate the lower few hundred meters of a 5-km-thick stratigraphic section exposed in the crater. The rocks encountered thus far are sedimentary; they record depositional and diagenetic environments considered to be $\sim 3.6 \pm 0.4$ billion years old [1]. The rocks include fluvial conglomerates, fluvial and deltaic sandstones, eolian sandstones, and lacustrine mudstones [2]. Modern eolian sand and dust deposits have also been examined [3].

The Mars Hand Lens Imager (MAHLI) is a 2-megapixel Bayer pattern micro-filtered color camera with a focusable macro lens mounted on the turret at the end of Curiosity's robotic arm [4]. MAHLI comes as close to robotic arm-deployed optical microscopy as yet achieved on a Mars rover mission. A copy of MAHLI, WATSON (Wide Angle Topographic Sensor for Operations and eNgineering), will accompany the SHERLOC (Scanning Habitable Environments with Raman \& Luminescence for Organics \& Chemicals) instrument [5] on NASA's next Mars rover, launching in 2020. MAHLI can focus on targets at working distances of $2.1 \mathrm{~cm}$ to infinity; typical images are $14-100 \mu \mathrm{m}$ per pixel in scale [6].

MAHLI was designed to be robust to challenging environments (eolian dust, diurnal temperature range, and launch, drill, and sieve vibration). The MAHLI design optimizes a scientific, engineering, and data downlink-constrained trade-space that (a) permits distinction of very fine sand from coarse silt (vital for rock depositional environment interpretation and potential for biosignature preservation in mudstones); (b) facilitates identification of rock, regolith, and eolian sediment properties as good as or better than a geologist's hand lens; (c) acquires images, mosaics, focus stacks, and stereo/multiple images for threedimensional views; and (d) all while having a sufficient field of view and focus range for high resolution imaging, context imaging, sample extraction documentation, and hardware inspection.

Figure 1 shows some example observations. MAHLI images have contributed to major mission results through direct observation of geologic targets and through science-enabling support imaging (hardware inspections and tool placement). MAHLI is vital for determining rock type and assisting in the interpretation of sediment depositional and diagenetic environments. MAHLI data are available from the NASA Planetary Data System (PDS) and raw images are posted within minutes of receipt on Earth on the NASA/California Institute of Technology/Jet Propulsion Laboratory web site [7]. 


\section{References:}

[1] B Thomson et al, Icarus 214 (2011), doi:10.1016/j.icarus.2011.05.002.

[2] J Grotzinger et al, Science 350 (2015), doi:10.1126/science.aac7575.

[3] M Minitti et al, J. Geophys. Res. Planets 118 (2013), doi:10.1002/2013JE004426.

[4] K Edgett et al, Space Sci. Rev. 170 (2012), doi:10.1007/s11214-012-9910-4.

[5] L Beegle et al, Lunar Planet. Sci. 48 (2017), abs. 2839, Lunar and Planetary Institute, Houston, TX.

[6] R Yingst et al, Geosci. Instrum. Method. Data Syst. 5 (2016), doi:10.5194/gi-5-205-2016.

[7] NASA PDS (http://pds-imaging.jpl.nasa.gov/volumes/msl.html); NASA/Caltech/JPL (http://mars.jpl.nasa.gov/msl/multimedia/raw/); accessed 13 February 2017.

[8] R Wiens et al, Elements 11 (2015), doi:10.2113/gselements.11.1.33.

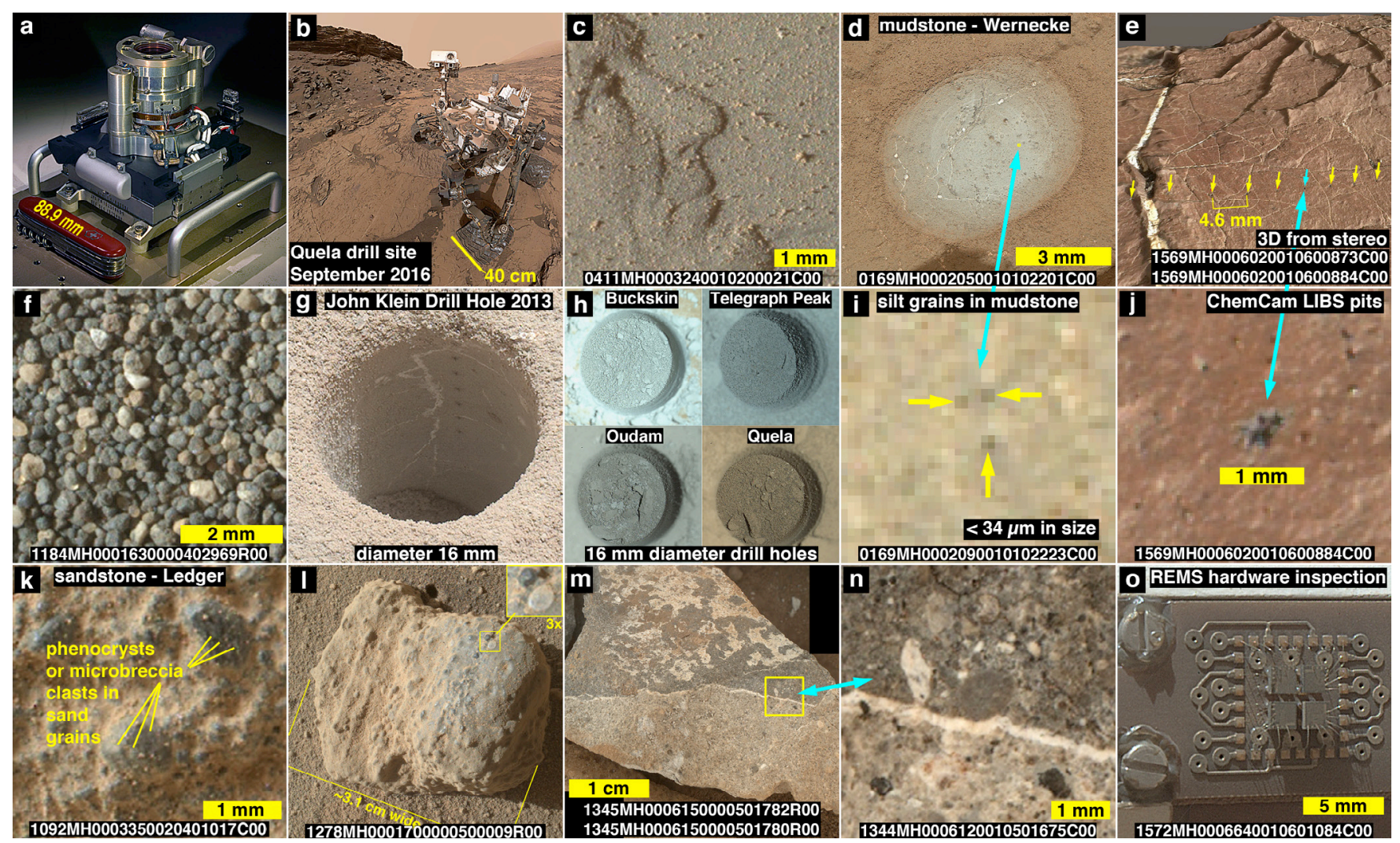

Figure 1. Example color images. (a) MAHLI camera head. (b) MAHLI mosaic of Curiosity rover; arm not visible because MAHLI is on the arm (try getting your arm in a "selfie" of yourself). (c) Mars dust deposited from suspension on U.S. cent on calibration target. (d) Mudstone with brushed surface made by Dust Removal Tool (DRT); arrow indicates area viewed in (i). (e) 3D rendering from MAHLI stereo pair showing ChemCam [8] Laser-Induced Breakdown Spectrometer (LIBS; target Dix Point) pits (arrows). (f) Eolian dune sand. (g) Sample extraction (drill) hole exposing veins; dark spots are from ChemCam LIBS. (h) Night views, illuminated by white light LEDs of identical exposure, showing color differences in mudstone drill cuttings from different strata. (i) Dark silt grains in mudstone; sizes constrained by four pixels. (j) ChemCam LIBS pit in red mudstone target Dix Point. (k) Phenocrysts or microbreccia clasts in lithic sand grains in mafic eolian sandstone. (l) Sandstone concretion, liberated by erosion from east Naukluft Plateau outcrop. (m) Mafic sandstone chip broken by rover wheel, exposing veins and altered (lighter-toned) rock; box indicates view in (n). (n) Details of altered sandstone. (o) Example of externally mounted hardware inspection on rover's meteorology (Rover Environmental Monitoring Station; REMS) boom. 